\title{
Uji Performansi Jaringan menggunakan Kabel UTP dan STP
}

\author{
KUKUH NUGROHO, AHMAD YOGI KURNIAWAN
}

Jurusan Teknik Telekomunikasi STT Telematika Telkom Purwokerto

Email: kukuh@st3telkom.ac.id

\begin{abstract}
ABSTRAK
Unshield Twisted Pair (UTP) dan Shield Twisted Pair (STP) merupakan tipe kabel untuk menghubungkan antar komputer sehingga dapat membentuk sebuah jaringan. Secara teori, maksimal panjang kabel yang diperbolehkan adalah 100 meter. Namun secara praktik, belum pernah diujikan tentang jarak maksimal antar dua komputer yang diperbolehkan ketika pilihan media menggunakan kabel UTP atau STP. Penelitian ini akan menguji performansi jaringan dimana media yang digunakan adalah kabel UTP cat6 dan STP cat5. Proses pengujian dilakukan dengan cara mengirimkan paket ICMP. Pada saat pengujian, ukuran dari paket ICMP yang digunakan adalah sebesar 1000 Byte yang dikirimkan sebanyak 50 kali. Dengan menggunakan informasi paket ICMP Reply tersebut, kemudian diukur kinerja jaringan yang meliputi latency, throughput, dan packet loss. Dari hasil pengujian didapatkan nilai latency jika digunakan kabel STP lebih kecil sekitar $13 \%$ dari penggunaan kabel UTP. Namun untuk mencapai packet loss sebesar 0\%, maksimal panjang kabel jika digunakan UTP cat6 adalah sebesar 256 meter, sedangkan untuk kabel STP lebih pendek yaitu sebesar 246 meter.
\end{abstract}

Kata kunci: UTP, STP, latency, throughput, packet loss.

\begin{abstract}
Unshield Twisted Pair (UTP) and Shield Twisted Pair (STP) are a cable type that used to connect between computers so that can build the network. Theoretically, the maximum cable length that allowed is 100 meters. However, in practice, it has never been tested about the maximum distance between two computers that allowed when media options used is UTP or STP cable. This research will be tested network performance when the media used is UTP cat6 and STP cat5. The testing process is done by sending ICMP packet. At the time of testing, the size of ICMP packet used is 1000 Bytes that is sent 50 times. By using information of ICMP "Reply" packet received by the sender computer, then it measures the network performance encompass latency, throughput, and packet loss. From the test results it is obtained that latency values if used STP cable is smaller about $13 \%$ than the use of UTP cable. However, to achieve packet loss close to the value of $0 \%$, the maximum cable length when UTP Cat6 used is 256 meters, while shorter STP cable is equal to 246 meters.
\end{abstract}

Keywords: UTP, STP, latency, throughput, packet loss. 


\section{PENDAhUlUAN}

Perkembangan teknologi jaringan komputer semakin maju, khususnya penggunaan media transmisi. Penggunaan media transmisi juga tidak terlepas dari peran layer 2 (data link) sebagai pengubah data fisik ke logic, begitupula sebaliknya. Aliran data fisik berupa deretan bit akan dikirimkan dari komputer pengirim ke penerima. Oleh komputer penerima, deretan bit tersebut akan diubah menjadi data logic. Diperlukan penggunaan teknologi untuk mengubah dari data fisik menjadi data logic. Salah satu teknologi yang terdapat di layer 2 (data link) adalah Ethernet.

Dalam mengubah data logic ke fisik (deretan bit), teknologi Ethernet menggunakan satuan bps (bit per second). Teknologi Ethernet sendiri mempunyai beberapa tipe, dimulai dari Ethernet, Fast Ethernet, sampai Gigabit Ethernet. Masing-masing tipe Ethernet memiliki kecepatan transfer bit yang berbeda-beda. Berikut adalah perbedaan kecepatan transfer bit dari masing-masing tipe Ethernet:

Tabel 1. Perbandingan tipe Ethernet (Yuan, 2014)

\begin{tabular}{|c|c|c|c|c|}
\hline & Ethernet & $\begin{array}{c}\text { Fast } \\
\text { Ethernet }\end{array}$ & $\begin{array}{c}\text { Gigabit } \\
\text { Ethernet }\end{array}$ & $\begin{array}{c}\text { 10-Gigabit } \\
\text { Ethernet }\end{array}$ \\
\hline $\begin{array}{c}\text { Kode } \\
\text { Standar }\end{array}$ & 802.3 & $802.3 \mathrm{u}$ & $802.3 \mathrm{z}$ & $802.3 \mathrm{ae}$ \\
\hline Bandwidth & $10 \mathrm{Mbps}$ & $100 \mathrm{Mbps}$ & $1 \mathrm{Gbps}$ & $10 \mathrm{Gbps}$ \\
\hline $\begin{array}{c}\text { Tipe } \\
\text { Media }\end{array}$ & $\begin{array}{c}\text { Kabel } \\
\text { Coaxial/Twisted } \\
\text { pair/Fiber optic }\end{array}$ & $\begin{array}{c}\text { Kabel } \\
\text { Twisted } \\
\text { pair/Fiber } \\
\text { optic }\end{array}$ & $\begin{array}{c}\text { Kabel Twisted } \\
\text { pair/Fiber optic }\end{array}$ & Kabel Fiber optic \\
\hline
\end{tabular}

Tabel 1 menjelaskan perbedaan kecepatan transfer bit dari sebuah interface yang menggunakan teknologi Ethernet. Tipe Ethernet paling awal adalah Ethernet dengan kecepatan transfer bit sebesar 10 Mbps. Pilihan tipe kabel yang digunakan adalah coaxial, twisted pair, ataupun fiber optic. Tabel 1 juga menjelaskan dengan semakin besar bandwidth yang diberikan oleh sebuah tipe Ethernet, tipe kabel yang digunakan juga harus menyesuaikan. Jika digunakan tipe kabel twisted pair, maka batas maksimal tipe Ethernet adalah Gigabit Ethernet.

Terdapat dua tipe kabel twisted pair yang digunakan untuk menghubungkan antar komputer yaitu UTP dan STP. Perbedaan utama antara kedua kabel twister pair tersebut terletak pada bentuk fisik kabel. Berikut adalah perbedaan bentuk fisik antara kabel UTP dan STP:

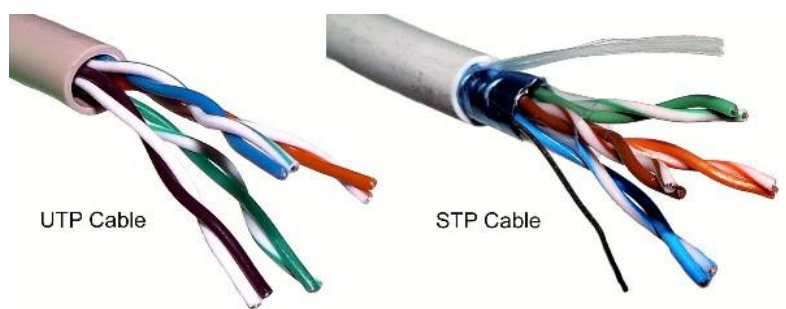

Gambar 1. Perbandingan kabel UTP dan STP (Tim Cisco, 2009) 
Jenis kabel STP menggunakan pembungkus kabel ganda dibandingkan dengan kabel jenis UTP. Perbedaan bentuk fisik kabel juga disesuaikan dengan peruntukan kabel. Kabel UTP lebih cocok digunakan untuk diimplementasikan pada pembangungan jaringan di dalam gedung (indoor), sedangkan STP lebih cocok untuk diimplementasikan di luar gedung (outdoor). Gambar 1 diatas menjelaskan bahwa bentuk fisik kabel STP lebih baik dibandingkan dengan UTP, sehingga apabila dibandingkan dari sisi performansi jaringan, penggunaan kabel STP juga harus lebih baik dibandingkan dengan penggunaan kabel UTP. Namun saat ini, kabel UTP mengalami perkembangan dari sisi bentuk fisik. Berikut tabel yang menunjukkan perkembangan kabel UTP:

Tabel 2. Perkembangan tipe Ethernet (Tim Cisco, 2009)

\begin{tabular}{|l|l|l|l|c|}
\hline $\begin{array}{c}\text { Tipe } \\
\text { Ethernet }\end{array}$ & Bandwidth & $\begin{array}{c}\text { Tipe kabel } \\
\text { UTP }\end{array}$ & Frekuensi & $\begin{array}{c}\text { Maksimal } \\
\text { Jarak (m) }\end{array}$ \\
\hline 10BASE-T & $10 \mathrm{Mbps}$ & Cat3 UTP & $16 \mathrm{MHz}$ & 100 \\
\hline 100BASE-TX & $100 \mathrm{Mbps}$ & Cat5 UTP & $100 \mathrm{MHz}$ & 100 \\
\hline 1000BASE-T & $1 \mathrm{Gbps}$ & Cat5e UTP & $100 \mathrm{MHz}$ & 100 \\
\hline 1000BASE-TX & $1 \mathrm{Gbps}$ & Cat6 UTP/STP & $250 \mathrm{MHz}$ & 100 \\
\hline 10GBASE-T & $10 \mathrm{Gbps}$ & Cat6a/Cat7 UTP & $500 / 600 \mathrm{MHz}$ & 100 \\
\hline
\end{tabular}

Jenis kabel UTP dimulai dari category 3 (Cat3). Jenis kabel ini diperuntukkan untuk Ethernet dengan tipe 10BASE-T. Bandwidth yang diberikan oleh Ethernet tipe ini adalah $10 \mathrm{Mbps}$. Kemudian muncul tipe Ethernet yang lain yaitu 100BASE-TX yang memberikan bandwidth sebesar 100 Mbps. Penggunaan Ethernet tipe 100BASE-TX menurut penjelasan tabel 2 harus menggunakan tipe kabel yang berbeda dengan tipe Ethernet 10BASE-T. Jenis kabel UTP category 5 (Cat5) sangat cocok untuk digunakan pada tipe Ethernet 100BASE-TX. Hal ini dikarenakan dengan semakin besar bandwidth yang diberikan oleh sebuah interface Ethernet, maka spesifikasi frekuensi yang digunakan oleh jenis kabel UTP juga harus lebih besar. Tabel 2 diatas menjelaskan bahwa jenis kabel UTP cat5 menggunakan frekuensi 100 $\mathrm{MHz}$. Begitupula dengan perkembangan jenis kabel UTP yang lain, dimulai dari cat5e, cat6, cat6a, sampai cat7. Nilai frekuensi yang digunakan pada jenis kabel UTP tersebut semakin besar. Begitupula untuk peruntukkan tipe Ethernet. Semakin tinggi jenis kategori dari kabel UTP, peruntukan kabel UTP tersebut juga untuk tipe Ethernet dengan bandwidth yang besar.

Dalam menghubungkan antar dua komputer dengan menggunakan kabel UTP/STP diperlukan peran dari NIC (Network Interface Card). Dalam interface card tersebut diperlukan peran protokol agar aliran bit data dapat dikirimkan dari komputer pengirim ke penerima. Saat ini, protokol yang banyak digunakan adalah Ethernet. Menurut data dari tipe Ethernet yang terdapat pada Tabel 2, semua tipe Ethernet mempunyai jarak maksimal panjang kabel yang sama yaitu sebesar 100 meter. Padahal apabila dilihat dari sisi tipe Ethernet, masing-masing tipe Ethernet memberikan besaran bandwidth yang berbeda. Selain itu, penggunaan jenis kabel UTP/STP juga khusus untuk tipe Ethernet tertentu. Hal ini disesuaikan dengan besaran nilai bandwidth yang diberikan oleh tipe Ethernet. Misalnya untuk tipe Ethernet 1000BASE-TX dengan bandwidth interface sebesar 1 Gbps, jenis kabel UTP yang digunakan adalah category 6 (cat6). Secara praktik, seharusnya dengan semakin tinggi bandwidth yang diberikan oleh sebuah NIC, disertai dengan penggunaan jenis kategori kabel UTP/STP, maka panjang maksimal kabel untuk menghubungkan antar komputer juga semakin bertambah. Oleh karena itu diperlukan penelitian agar dihasilkan kesimpulan secara praktik tentang teori penggunaan jenis kabel UTP/STP dengan maksimal panjang kabel yang masih diperbolehkan ketika kabel tersebut digunakan untuk membuat konsep topologi peerto-peer dengan hanya menghubungkan dua komputer secara langsung. 
Jaringan komputer didefinisikan sebagai konsep dalam menghubungkan antar node. Pengertian dari node adalah sebuah perangkat. Jaringan komputer akan menghubungkan antar node dengan menggunakan bantuan media. Kabel UTP/STP merupakan solusi sebagai media penghubung antar node selain wireless. Perangkat dalam konsep sebuah jaringan dibagitidak ada paket yang hilang selama proses pengiriman paket ICMP dalam dua jenis; perangkat akhir dan perangkat penghubung. Contoh dari perangkat akhir adalah komputer. Apabila komputer yang dihubungan lebih dari dua, maka diperlukan perangkat penghubung, misalnya switch atau router. (Nugroho, 2016)

Sebelumnya telah dilakukan penelitian dengan menggunakan pilihan kategori kabel UTP yang berbeda. Kategori kabel UTP yang digunakan dalam penelitian adalah UTP cat5 dengan kabel STP. Apabila digunakan acuan tabel 2, perbandingan antara kabel UTP cat5 dengan kabel STP belum seimbang. Dari hasil penelitian diperoleh data bahwa maksimal panjang kabel yang diperbolehkan jika digunakan kabel UTP cat5 adalah sebesar 135 meter. Apabila panjang kabel UTP dibuat lebih besar 135 meter, akan terdapat packet loss. Namun pada penggunaan kabel STP cat5, masih belum diperoleh kesimpulan akhir tentang panjang maksimal kabel yang diperbolehkan karena pada saat proses pengujian hanya sebesar 200 meter. Pada jarak tersebut masih diperoleh nilai packet loss sebesar $0 \%$. (Nugroho, dkk, 2016)

Ahmed juga melakukan penelitian tentang uji performansi kabel twisted pair dari beberapa vendor pembuat kabel. Parameter yang digunakan untuk menguji adalah panjang maksimal kabel dan delay. Dari hasil pengujian diperoleh rata-rata panjang maksimal kabel twisted pair adalah sebesar 87,78 meter dengan nilai delay sebesar 580 ns. (Mahmud, dkk, 2008)

Pada penelitian sebelumnya, tipe kabel UTP cat5 yang digunakan sebagai objek penelitian masih belum berimbang jika dibandingkan dengan penggunaan kabel STP. Berdasarkan acuan Tabel 2, tipe kabel UTP yang harus digunakan agar lebih seimbang jika dibandingkan dengan kabel STP adalah dengan penggunaan kabel UTP category 6 (cat6). Nilai frekuensi dari kedua jenis kabel twisted pair tersebut adalah sama yaitu $250 \mathrm{MHz}$. Sehingga penelitian ini menggunakan tipe kabel UTP category 6 (cat6) dibandingkan performansi jaringan dengan kabel STP. Panjang kabel yang digunakan pada masing-masing kabel adalah sebesar 300 meter. Parameter yang digunakan untuk menguji jaringan adalah latency, throughput, dan packet loss. Sedangkan topologi jaringan yang digunakan adalah peer-to-peer dengan mengirimkan paket ICMP antar komputer. ICMP (Internet Control Message Protocol) sendiri merupakan sebuah protokol yang digunakan untuk proses pengecekan keberadaan komputer lawan. Karakteristik yang dimiliki oleh protokol ICMP adalah adanya balasan berupa pengiriman paket ICMP Reply dari komputer tujuan sebagai balasan dari pengiriman paket ICMP Request yang dikirimkan oleh komputer sumber.

\section{METODOLOGI}

\subsection{Perancangan Jaringan}

Pembuatan konsep jaringan awal diperlukan untuk menentukan hasil keluaran dari proses pengujian. Persiapan yang diperlukan terdiri dari perangkat dan media, dalam hal ini adalah kabel UTP cat6 dan STP cat5. Selain perangkat juga harus disiapkan topologi jaringan yang akan digunakan. Berikut adalah diagram alir pembuatan konsep jaringan dari awal pembuatan topologi sampai pengambilan data: 


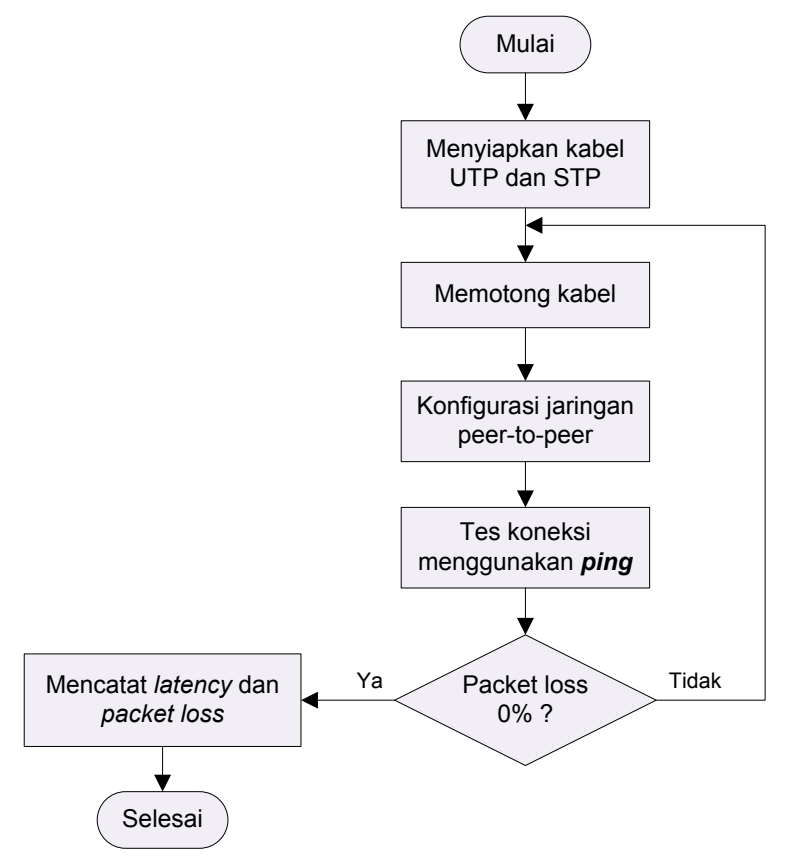

\section{Gambar 2. Diagram alir perancangan sistem jaringan}

Gambar 2 diatas menjelaskan proses pengujian untuk mengukur perfomansi jaringan dimana media yang digunakan adalah kabel UTP dan STP. Tahap pertama adalah menyiapkan kabel UTP dan STP yang akan dijadikan sebagai media penghubung antar komputer. Panjang kabel awal yang disiapkan untuk proses pengujian adalah sebesar 300 meter, baik pada kabel UTP ataupun STP. Kemudian kabel dipotong, rata-rata setiap 5 meter. Setiap pengurangan panjang kabel 5 meter, kemudian akan ditentukan nilai latency latency dan packet loss. Dalam mengukur kedua parameter tersebut digunakan program ping. Paket ICMP akan dikirimkan dari komputer sumber ke tujuan. Konsep topologi jaringan yang digunakan pada proses pengujian adalah peer-to-peer.

Penggunaan panjang kabel awal 300 meter diasumsikan bahwa pada jarak tersebut performansi jaringan berada pada keadaan sangat buruk. Dalam artian, tidak ditemukan adanya nilai latency ataupun packet loss. Dengan mengurangkan panjang kabel setiap 5 meter diharapkan terdapat pengurangan nilai dan packet loss. Pada proses pengujian diasumsikan tidak ada trafik dari komputer lain yang mengganggu, karena konsep topologi jaringan yang digunakan adalah peer-to-peer. Pengujian jaringan peer-to-peer akan dilakukan terus setiap pengurangan panjang kabel sebesar 5 meter. Proses pengujian jaringan akan dihentikan disaat ditemukan nilai packet loss sebesar $0 \%$. Artinya dengan prosentase packet loss sebesar $0 \%$, jaringan sudah dalam keadaan baik. Dengan kata lain, kabel UTP ataupun STP layak untuk digunakan pada jarak tersebut. Setelah ditemukan nilai packet loss sebesar 0\%, kemudian dicatat nilai latency dan jarak ideal ketika kabel UTP dan STP digunakan sebagai media. Rekomendasi jarak ideal akan didapatkan setelah ditemukan adanya penurunan nilai packet loss sampai $0 \%$. Namun, jarak ideal yang diperoleh terlebih dahulu akan dicocokkan dengan standarisasi QoS (Quality of Service) yang dikeluarkan oleh THIPON.

\subsection{Topologi Jaringan}

Topologi jaringan yang digunakan untuk proses uji performansi adalah peer-to-peer. Ciri khusus dari konsep jaringan peer-to-peer adalah adanya hubungan langsung antara dua komputer, dimana media yang digunakan adalah kabel. Karena digunakan topologi jaringan peer-to-peer, maka trafik data hanya berasal dari dua komputer yang saling terhubung. Pada 
skenario pengujian jaringan tidak diberikan trafik pengganggu dari komputer lain. Berikut adalah gambar topologi jaringan yang digunakan pada saat proses pengujian:

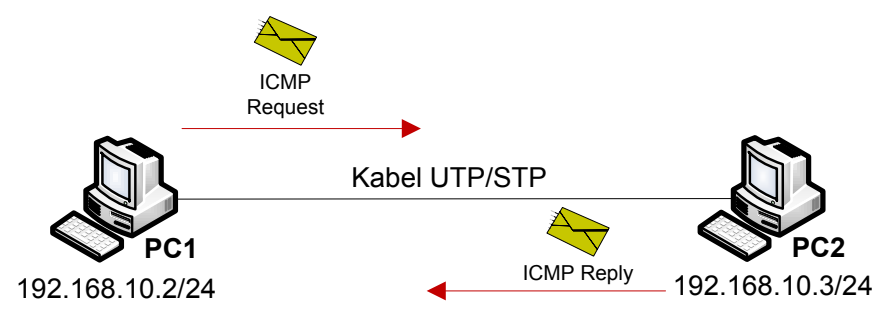

Gambar 3. Perencanaan topologi jaringan

Gambar 3 menjelaskan konsep perencanaan topologi jaringan untuk proses uji performansi, dimana parameter performansi yang digunakan adalah latency dan packet loss. Pengujian performansi dilakukan pada panjang kabel UTP/STP yang berbeda. Perhitungan latency dan packet loss dilakukan dengan menggunakan program ping. Sebelum program ping bisa digunakan, maka antar komputer harus diberikan alamat IP. Pada proses perencanaan jaringan, masing-masing komputer diberikan alamat IP dengan menggunakan kelas C. Berikut adalah tabel pengalamatan IP untuk masing-masing komputer:

Tabel 3. Pengalamatan IP pada komputer

\begin{tabular}{|c|c|c|}
\hline Komputer & Alamat IP & Subnet Mask \\
\hline PC1 & 192.168 .10 .2 & 255.255 .255 .0 \\
\hline PC2 & 192.168 .10 .3 & 255.255 .255 .0 \\
\hline
\end{tabular}

Tabel 3 menjelaskan alamat IP dari masing-masing komputer. Alamat network yang digunakan oleh masing-masing komputer adalah 192.168.10.0, dengan nilai subnet mask yang digunakan adalah 255.255.255.0.

\subsection{Mekanisme Pengukuran}

Pengukuran uji performansi jaringan pada penggunaan kabel UTP dan STP dilakukan dengan menggunakan dua komputer yang terhubung langsung. Tipe pengkabelan yang digunakan adalah crossover. Dalam melakukan uji performansi, terdapat tiga parameter yang diujikan antara lain;latency, throughput, dan packet loss. Untuk menghitung ketiga parameter tersebut digunakan program ping yang dijalankan pada sistem operasi Ubuntu. Ketika program ping dijalankan, sebenarnya terdapat paket yang dipertukarkan antar komputer yaitu paket ICMP (Internet Control Message Protocol). Terdapat komputer yang memulai untuk mengirimkan paket ICMP, paket tersebut dinamakan sebagai paket ICMP Request. Sedangkan komputer yang menerima paket ICMP Request akan memberikan balasan berupa pengiriman paket ICMP Reply. Sebelum program ping dapat digunakan antar komputer, terdapat tahapan proses pemberian alamat IP antar komputer. Alamat IP yang diberikan pada komputer seperti yang terlihat pada tabel 3 . Setelah alamat IP diberikan pada masingmasing komputer, kemudian program ping dijalankan pada jendela terminal pada sistem operasi Ubuntu. Dengan menuliskan alamat IP tujuan pada jendela terminal tersebut, maka nantinya akan ada balasan berupa pengiriman paket ICMP Reply. Dari pengiriman paket ICMP Reply tersebut, nantinya bisa dilihat nilai latency, throughput, dan packet loss.

\subsubsection{Pengukuran Latencydan Packet Loss}

Latency adalah waktu yang dibutuhkan oleh sebuah data, ketika data tersebut dikeluarkan oleh perangkat pengirim sampai data diterima oleh perangkat penerima. Pengiriman data dengan waktu yang singkat akan dikatakan bahwa performansi jaringan dalam keadaan baik. 
Artinya dengan nilai latency kecil akan menjadikan performansi sebuah jaringan menjadi baik. Parameter latency diukur dengan menggunakan program ping, dimana sistem operasi yang digunakan adalah Ubuntu. Paket data yang dikirim pada proses pengujian yaitu sebesar 1000 byte yang dikirimkan sebanyak 50 kali. Pada sistem operasi Ubuntu, program ping muncul pada jendela Terminal.

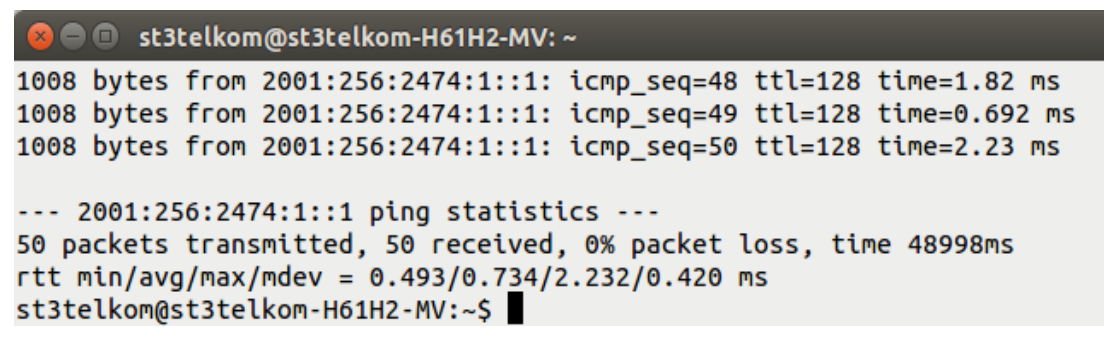

Gambar 4. Tampilan hasil program ping pada jendela Terminal

Gambar 4 menjelaskan hasil tampilan dari program ping. Ketika alamat IP dari komputer tujuan dituliskan, maka akan muncul statistik dari nilai latency dan jumlah paket yang hilang selama proses pengiriman paket ICMP Request. Dari hasil keluaran, untuk menghitung nilai latency bisa dilihat dari rata-rata nilai RTT (Round Trip Time). RTT disini adalah waktu tempuh bolak balik, artinya parameter yang dituliskan mengacu pada pengiriman paket dari komputer pengirim ke komputer penerima, kemudian paket dikirim kembali dari komputer penerima ke pengirim. Waktu tempuh RTT dapat diartikan sebagai istilah latency. Selain ditemukan nilai latency, juga bisa ditemukan nilai dari packet loss. Setelah diketahui nilai latency, kemudian akan dicocokkan dengan standar nilai latency yang dikeluarkan oleh THIPON. Berikut daftar standar nila latency yang dikeluarkan oleh THIPON:

Tabel 4. Standarisasi Latency dari THIPON (ETSI, 1999)

\begin{tabular}{|c|c|}
\hline Kategori Latency & Besar Delay \\
\hline Sangat bagus & $<150 \mathrm{~ms}$ \\
\hline Bagus & $<250 \mathrm{~ms}$ \\
\hline Sedang & $<350 \mathrm{~ms}$ \\
\hline Buruk & $<450 \mathrm{~ms}$ \\
\hline
\end{tabular}

Menurut standarisasi nilai latency yang dikeluarkan oleh THIPON, latency dapat dikatakan baik jika nilai latency tersebut tidak lebih dari $250 \mathrm{~ms}$. Pada proses penelitian, pengambilan data akan didasarkan pada acuan nilai latency. Kategori nilai latency yang digunakan yaitu dibawah nilai $250 \mathrm{~ms}$, atau dalam kategori "bagus".

\subsubsection{Pengukuran Throughput}

Throughput merupakan besaran kecepatan pengiriman/penerimaan data secara nyata per detik. Biasanya nilai throughput akan lebih kecil dari nilai bandwidth. Perhitungan nilai throughput akan bisa didapatkan setelah nilai latency. Sehingga terdapat hubungan antara nilai throughput dengan latency. Berikut persamaan untuk menentukan nilai throughput dari latency: (Nugroho, 2016)

$$
\text { Throughput }=\frac{\text { ukuran data terima (bit) }}{\text { latency }(\text { detik })}
$$


Dari Persamaan (1), pengukuran nilai throughput akan didapatkan setelah diketahui nilai latency. Pengukuran nilai latency dilakukan dengan cara menggunakan program ping yang diaktifkan pada komputer pengirim.

\section{PENGUJIAN DAN HASIL PEMBAHASAN}

Data hasil dari pengujian unjuk kerja jaringan pada penggunaan kabel UTP dan STP dilakukan dengan menguji nilai latency, throughput, dan packet loss. Pengujian dilakukan dengan topologi jaringan peer to peer antara dua buah komputer yang saling terhubung langsung. Panjang kabel UTP dan STP pada saat pengujian dimulai dari 300 meter. Kemudian langkah pengujian diulangi dengan panjang kabel yang lebih pendek. Rata-rata nilai pengurangan dari panjang kabel sebesar 5 meter. Parameter awal yang akan dicari adalah nilai latency. Setelah nilai latency didapatkan kemudian akan dicocokkan dengan data standarisasi nilai latency yang dikeluarkan oleh THIPON. Proses pengujian jaringan akan dihentikan ketika didapatkan nilai latency dalam kategori bagus yaitu kurang dari 250 ms.

\subsection{Pengujian Menggunakan Kabel UTP}

Langkah awal pengujian dilakukan dengan menggunakan kabel UTP. Panjang kabel awal yang digunakan adalah 300 meter. Kemudian panjang kabel dikurangi, rata-rata sebesar 5 meter. Dari penggunaan masing-masing panjang kabel yang berbeda, kemudian akan dilihat nilai latency, throughput, dan packet loss. Berikut adalah data hasil pengukuran dengan menggunakan kabel UTP cat6:

\section{Tabel 5. Hasil pengukuran uji performansi menggunakan kabel UTP cat6}

\begin{tabular}{|c|c|c|c|}
\hline $\begin{array}{c}\text { Panjang } \\
\text { Kabel }(\mathbf{m})\end{array}$ & $\begin{array}{c}\text { Latency } \\
(\mathbf{m s})\end{array}$ & $\begin{array}{c}\text { Throughput } \\
\text { (Mbps) }\end{array}$ & $\begin{array}{c}\text { Packet } \\
\text { Loss }(\%)\end{array}$ \\
\hline 300 & NA & NA & NA \\
\hline 280 & NA & NA & NA \\
\hline 275 & 0.582 & 13.847 & 29 \\
\hline 270 & 0.664 & 12.138 & 13 \\
\hline 265 & 0.551 & 14.635 & 7 \\
\hline 260 & 0.558 & 14.451 & 6 \\
\hline 256 & 0.533 & 15.129 & 0 \\
\hline 254 & 0.582 & 13.863 & 0 \\
\hline 252 & 0.560 & 14.391 & 0 \\
\hline
\end{tabular}

Tabel 5 menjelaskan hasil pengukuran dengan dimana kabel yang digunakan adalah UTP cat6. Nilai latency, throughput, dan packet loss masih belum didapatkan pada penggunaan panjang kabel 300 meter. Menurut data hasil pengukuran pada Tabel 5 terlihat bahwa nilai latency, throughput, dan packet loss akan terlihat pada penggunaan kabel dengan panjang minimal 275 meter. Nilai packet loss yang dihasilkan sebesar $29 \%$ dengan nilai latency 0,582 ms. Jumlah paket ICMP yang dikirimkan untuk melihat uji performansi adalah sebesar 50 paket ICMP. Dari pengiriman paket ICMP tersebut kemudian akan dilihat berapa banyak jumlah paket yang hilang selama dalam proses pengiriman. Begitupula dengan nilai latency. Tabel nilai latency yang didapatkan dari tabel 5 diatas merupakan nilai latency rata-rata dari waktu pengiriman paket ICMP dari komputer sumber ke tujuan. Hasil keluaran dari uji performansi jaringan akan dicocokkan dengan nilai standarisasi yang dikeluarkan oleh THIPON. Proses pencocokkan nilai diperlukan agar nilai dari parameter uji performansi dapat dikategorikan menurut klasifikasi-nya. THIPON sendiri mengklasifikasikan empat kategori penilaian dari sebuah parameter, misalnya parameter acuan yang digunakan adalah latency. Kategori yang disebutkan oleh THIPON terdiri dari sangat bagus, bagus, sedang, dan buruk. 
Pada proses pengujian, target yang akan dicapai adalah pada kategori sangat bagus, dimana minimal nilai latency yang didapatkan harus kurang dari $150 \mathrm{~ms}$.

Selain menggunakan acuan target nilai latency dalam kategori sangat bagus, parameter lain yang juga dijadikan target pengujian hasil uji performansi jaringan adalah packet loss. Jumlah paket yang hilang selama pengiriman paket ICMP sebesar 50 paket ICMP harus $0 \%$. Artinya tidak ada paket yang hilang selama proses pengiriman paket ICMP dari komputer sumber ke tujuan. Dari data hasil pengujian pada tabel 5 terlihat bahwa packet loss $0 \%$ akan didapatkan jika panjang kabel UTP yang digunakan maksimal sebesar 256 meter. Data nilai latency dari tabel 5 juga terlihat bahwa pada penggunaan panjang kabel 256 meter dihasilkan nilai latency sebesar 0,533 ms. Apabila dicocokkan dengan standarisasi nilai yang dikeluarkan oleh THIPON, nilai latency 0,533 ms sudah dikategorikan sangat bagus. Pada keterangan tabel 5 juga didapatkan nilai throughput pada jarak 256 meter yaitu sebesar 15,129 Mbps. Penghitungan nilai throughput didapatkan menggunakan Persamaan (1).

\subsection{Pengujian Menggunakan Kabel STP}

Pada pengujian yang dilakukan sebelumnya, dimana terdapat dua komputer yang dihubungkan dengan menggunakan konsep jaringan peer-to-peer. Kabel twisted pair digunakan untuk menghubungkan dua komputer tersebut. Jenis kabel twisted pair menggunakan UTP cat5 dan kabel STP, kemudian dibandingkan performansi jaringan dengan menggunakan kedua jenis kabel twisted pair tersebut. Paket ICMP dengan ukuran 1000 Byte dikirimkan dari komputer pengirim ke tujuan. Kecepatan transfer bit data yang digunakan antar dua interface komputer adalah sebesar $100 \mathrm{Mbps}$. Hal ini dikarenakan tipe Ethernet yang digunakan adalah FastEthernet. Dari data hasil pengujian dapat disimpulkan bahwa penggunaan kabel STP memberikan performansi yang lebih baik dibandingkan dengan penggunaan kabel UTP cat5. Pada penggunaan kabel UTP cat5, nilai packet loss sebesar 0\% masih dapat diperoleh pada saat maksimal panjang kabel 135 meter. Penggunaan kabel UTP cat5 lebih dari 135 meter akan didapatkan adanya pengiriman paket yang hilang ketika paket tersebut dikirimkan dari komputer pengirim ke tujuan. Sedangkan penggunaan kabel STP bisa mencapai lebih dari 200 meter. Pada penggunaan panjang kabel tersebut, belum didapatkan didapatkan adanya paket yang hilang (Nugroho, dkk, 2016). Oleh karena itu pada pengujian kali ini akan digunakan tipe kabel STP dengan menggunakan panjang kabel mencapai 300 meter. Dari hasil data yang diperoleh kemudian dibandingkan dengan data hasil percobaan dengan menggunakan kabel UTP cat6. Berikut adalah data hasil pengujian dengan menggunakan kabel STP:

Tabel 6. Hasil pengukuran uji performansi menggunakan kabel STP

\begin{tabular}{|c|c|c|c|}
\hline Panjang Kabel (m) & Latency (ms) & Throughput (Mbps) & Packet Loss (\%) \\
\hline 300 & NA & NA & NA \\
\hline 280 & NA & NA & NA \\
\hline 275 & 0.553 & 14.590 & 73 \\
\hline 270 & 0.583 & 13.820 & 65 \\
\hline 265 & 0.528 & 15.282 & 52 \\
\hline 260 & 0.545 & 14.796 & 25 \\
\hline 256 & 0.446 & 18.094 & 10 \\
\hline 254 & 0.446 & 18.094 & 9 \\
\hline 252 & 0.500 & 16.117 & 2 \\
\hline 248 & 0.487 & 16.236 & 0 \\
\hline 246 & 0.492 & 16.379 & 0 \\
\hline 245 & 0.494 & 16.334 & \\
\hline
\end{tabular}


Pada penggunaan panjang kabel yang sama yaitu 300 meter, didapatkan hasil yang sama pada saat menggunakan kabel UTP cat6. Paket ICMP yang dikirimkan oleh komputer pengirim akan teredam sempurna. Artinya nilai dari parameter baik latency, throughput, dan packet loss tidak didapatkan. Hal ini disebabkan karena paket yang dikirimkan tidak bisa sampai ke komputer tujuan. Ketika panjang kabel STP yang digunakan untuk menghubungkan dua komputer dibuat lebih kecil yaitu sebesar 275 meter sudah didapatkan nilai packet loss. Begitupula dengan nilai latency. Artinya paket ICMP yang dikirimkan oleh komputer pengirim ada yang sampai ke komputer penerima, walaupun ada sebagian packet loss pada saat packet ICMP dikirimkan dari komputer pengirim ke penerima. Jika dibandingkan performansi jaringan disaat menggunakan kabel UTP cat6 dan STP cat5 terdapat perbedaan angka. Pada penggunaan kabel UTP cat6 dengan panjang kabel 275 meter, didapatkan nilai packet loss sebesar $29 \%$. Sedangkan pada penggunaan kabel STP didapatkan hasil sebesar $73 \%$. Artinya apabila dilihat dari parameter packet loss dengan penggunaan panjang kabel yang sama, penggunaan kabel UTP cat6 memberikan nilai yang lebih baik sebesar $151,72 \%$ dibandingkan jika digunakan kabel STP. Namun, apabila dibandingkan dari sisi latency, penggunaan kabel UTP cat6 memberikan nilai yang relatif sama. Apabila digunakan kabel UTP cat6 akan didapatkan nilai latency sebesar 0,582 ms. Sedangkan pada penggunaan kabel STP memberikan sedikit perbaikan sebesar 5,24\% yaitu di angka 0,553 ms. Walaupun proses pengiriman paket bisa sedikit lebih cepat jika dibandingkan pada saat menggunakan kabel UTP cat6, namun dari sisi parameter packet loss, penggunaan kabel UTP jauh lebih bagus.

Berdasarkan perbandingkan data packet loss antara hasil yang didapatkan pada Tabel 5 dan Tabel 6 . Untuk mencapai nilai packet loss $0 \%$ penggunaan kabel UTP cat6 juga memberikan hasil yang lebih baik dibandingkan dengan menggunakan kabel STP. Berdasarkan data dari tabel 5, nilai packet loss sebesar $0 \%$ masih bisa didapatkan ketika panjang kabel UTP cat6 yang digunakan maksimal sebesar 256 meter. Sedangkan jika digunakan kabel STP, untuk mendapatkan packet loss sebesar $0 \%$ maksimal panjang kabel digunakan sebesar 246 meter. Dari data packet loss bisa dilihat uji performansi disaat digunakan kabel UTP cat6 lebih baik sebesar 4,07\% jika dibandingkan pada saat menggunakan kabel STP.

Pengujian dilakukan dengan cara mengirimkan paket ICMP sebanyak 50 kali. Parameter awal yang akan dilihat adalah besaran packet loss. Tingkat kegagalan dalam proses pengiriman paket ICMP akan dijadikan sebagai acuan untuk menentukan besaran parameter yang lain, seperti latency dan throughput. Program yang digunakan untuk menghitung nilai packet loss adalah ping, dimana sistem operasi yang digunakan pada masing-masing komputer adalah Ubuntu. Selain didapatkan nilai packet loss, ketika paket ICMP dikirimkan dari komputer pengirim ke tujuan juga akan didapatkan nilai latency. Jika digunakan kabel STP, nilai latency yang didapatkan pada penggunaan panjang kabel 246 meter adalah sebesar 0,492 ms. Perhitungan nilai latencymenggunakan maksimal panjang kabel yang masih bisa menghasilkan nilai packet loss sebesar $0 \%$. Dari data yang terdapat pada tabel 6 , nilai packet loss sebesar $0 \%$ masih bisa didapatkan pada penggunaan panjang kabel STP sebesar 246 meter. Selain nilai latency, parameter lain yang bisa didapatkan adalah throughput. Jika diketahui nilai latency sebesar 0,492 ms, maka akan dengan menggunakan Persamaan (1) akan didapatkan nilai throughput sebesar 16,379 Mbps.

\subsection{Perbandingan Nilai Latency}

Perhitungan nilai latency didapatkan dengan menggunakan program ping. Nilai latency akan didapatkan setelah komputer pengirim menerima paket balasan yaitu berupa pengiriman paket ICMP Reply dari komputer penerima. Waktu yang dibutuhkan dari awal paket ICMP Request dikirimkan sampai mendapatkan balasan berupa pengiriman paket ICMP Reply 
dinamakan sebagai latency. Berdasarkan data hasil pengujian yang didapatkan pada tabel 5 dan 6 didapatkan nilai latency yang berbeda disaat menggunakan kabel UTP cat6 dan STP cat5. Perhitungan nilai latency dimulai dari penggunaan panjang kabel 300 meter sampai 252 meter untuk kabel UTP cat6. Sedangkan pada penggunaan kabel STP sedikit lebih panjang yaitu sampai pada panjang kabel 245 meter. Perbedaan penggunaan panjang kabel yang digunakan untuk proses pengujian dikarenakan parameter acuan yang digunakan untuk menentukan hasil uji performansi jaringan adalah packet loss. Terdapat perbedaan penggunaan panjang kabel yang masih bisa digunakan, dimana pada penggunaan panjang kabel tersebut masih bisa didapatkan nilai packet loss sebesar $0 \%$. Berikut adalah grafik perbedaan nilai latency pada penggunaan kabel UTP cat6 dan STP cat5 pada masing-masing penggunaan panjang kabel yang berbeda:

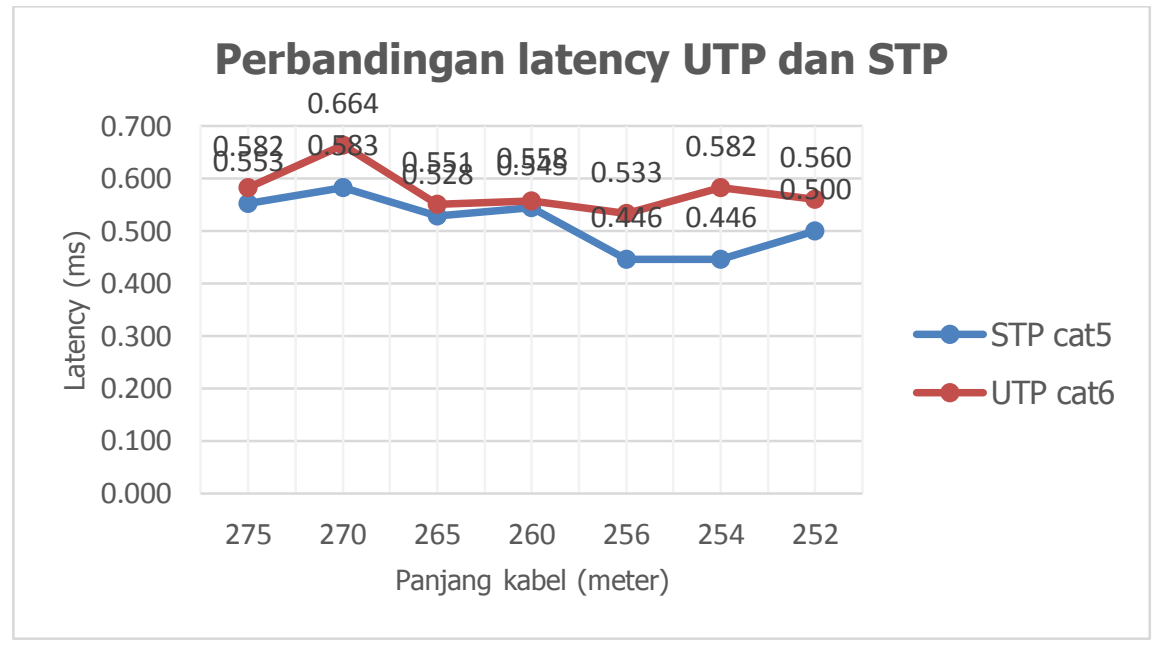

\section{Gambar 5. Perbandingan nilai latency pada panjang kabel yang berbeda}

Apabila dilihat dari perbandingan data latency pada Gambar 5 terlihat bahwa penggunaan kabel STP cat5 mempunyai performansi yang lebih baik dibandingkan dengan menggunakan kabel UTP cat6. Nilai rata-rata latency jika digunakan kabel STP relatif lebih kecil sekitar $13 \%$ dibandingkan pada penggunaan kabel UTP. Namun jika dilihat dari sisi packet loss, penggunaan kabel STP lebih jelek dibandingkan dengan menggunakan kabel UTP. Hal ini sesuai dengan perbandingan nilai packet loss pada tabel 5 dan tabel 6 . Jadi terdapat ketidaksamaan dari hasil uji performansi jika dilihat dari parameter latency dan packet loss. Nilai latency yang lebih kecil tidak menjamin adanya packet loss yang lebih kecil juga. Hal ini terbukti pada penggunaan kabel STP.

\section{KESIMPULAN}

Hasil dari pengujian jaringan peer-to-peer dengan menggunakan kabel UTP cat6 dan STP diperoleh kesimpulan bahwa ada beberapa sisi dimana penggunakan kabel UTP cat6 lebih baik dibandingkan dengan kabel STP. Jika dilihat dari pengukuran parameter packet losS, penggunaan kabel UTP cat6 dengan panjang maksimal sampai 256 meter masih didapatkan nilai packet loss $0 \%$. Berbeda ketika digunakan kabel STP. Untuk mencapai nilai packet loss sebesar 0\%, maksimal panjang kabel yang diperbolehkan bisa sampai 246 meter. Jadi penggunaan kabel UTP cat6 memberikan efisiensi penggunaan kabel yang lebih baik dibandingkan STP yaitu sekitar 4,07\%. Namun apabila dilihat dari sisi parameter nilai latency diperoleh hasil yang berbeda. Penggunaan kabel STP memberikan nilai latency yang lebih baik sekitar 13\% dibandingkan dengan menggunakan kabel UTP cat6. 


\section{DAFTAR RUJUKAN}

Yuan. (2014). Ethernet. Dipetik pada 5 Desember 2016 dari http://pt.slideshare.net/tungyuanlee/chap1-ethernet-introduction.

Tim Cisco. (2009). CCNA Exploration 4.0 Network Fundamentals. USA: Cisco System, Inc.

Nugroho, K. (2016). Jaringan Komputer Menggunakan Pendekatan Praktis. Kebumen: Media Tera.

Nugroho, K., \& Oktaviani, W. (2016). Pengukuran Unjuk Kerja Jaringan Pada Penggunaan Kabel UTP dan STP. Seminar Nasional Teknologi Informasi dan Multimedia 2016.

Mahmud, A. F., \& Abdallah, M. I. (2008). Performance Testing on Twisted Pair Cables. Journal of Computer Systems, Networks, and Communications.

ETSI. (1999). Telecommunications and Internet Protocol Harmonization Over Networks (TIPHON). General aspects of Quality of Service (QOS). France: European Telecommunications Standards Institute 2000.

Tonapa, O., Rahmiati, P., \& Komba, D. (2014). Analisis Performansi Konektifitas Pada Jaringan Wireless Broadband di Bandung. Jurnal Elkomika. 2(2): 162-170. 